\title{
Toxicokinetics and Physiologically Based Pharmacokinetic Modeling of the Shellfish Toxin Domoic Acid in Nonhuman Primates ${ }^{\text {\} }$
}

\author{
Jing Jing, Rebekah Petroff, Sara Shum, Brenda Crouthamel, Ariel R. Topletz, Kimberly S. Grant, \\ Thomas M. Burbacher, and Nina Isoherranen
}

\begin{abstract}
Department of Pharmaceutics (J.J., S.S., A.R.T., N.I.), Department of and Environmental and Occupational Health Sciences (R.P., B.C., K.S.G., T.M.B.), Center on Human Development and Disability (K.S.G., T.M.B.), and Infant Primate Research Laboratory, Washington National Primate Research Center, University of Washington, Seattle, Washington
\end{abstract} (K.S.G., T.M.B.)

Received September 4, 2017; accepted November 13, 2017

\begin{abstract}
Domoic acid (DA), a neurotoxin, is produced by marine algae and has caused toxications worldwide in animals and humans. However, the toxicokinetics of DA have not been fully evaluated, and information is missing on the disposition of DA following oral exposures at doses that are considered safe for human consumption. In this study, toxicokinetics of DA were investigated in cynomolgus monkeys following single doses of $5 \mu \mathrm{g} / \mathrm{kg}$ DA intravenously, $0.075 \mathrm{mg} / \mathrm{kg}$ DA orally, and $0.15 \mathrm{mg} / \mathrm{kg}$ DA orally. After intravenous dosing, DA had a systemic clearance of $124 \pm$ $71(\mathrm{ml} / \mathrm{h}) / \mathrm{kg}$, volume of distribution at steady state of $131 \pm$ $71 \mathrm{ml} / \mathrm{kg}$ and elimination half-life of $1.2 \pm 1.1$ hours. However, following oral dosing, the average terminal half-life of DA was 11.3 \pm 2.4 hours, indicating that DA disposition follows flip-flop kinetics
\end{abstract}

with slow, rate-limiting absorption. The absorption of DA was low after oral dosing with absolute bioavailability of $6 \% \pm 4 \%$. The renal clearance of DA was variable $[21-152(\mathrm{ml} / \mathrm{h}) / \mathrm{kg}]$ with $42 \% \pm$ $11 \%$ of the intravenous DA dose recovered in urine. A physiologically based pharmacokinetic model was developed for DA in monkeys and humans that replicated the flip-flop kinetics observed after oral administration and allowed simulation of urinary excretion and brain and kidney distribution of DA following intravenous and oral dosing. This study is the first to characterize DA disposition at exposure levels close to the current estimated tolerable daily intake and to mechanistically model DA disposition in a model species, providing important information of the toxicokinetics of DA for human safety assessment.

\section{Introduction}

Domoic acid (DA, Fig. 1) is a neurotoxic kainic acid and glutamate analog that binds to $\alpha$-amino-3-hydroxy-5-methylisoxazole-4propionate (AMPA) and kainate receptors, resulting in lesions in the hippocampus and amygdala (Pulido, 2008). DA is produced by several Pseudo-nitzschia algal species in seawater (Mos, 2001). As Pseudonitzschia blooms are initiated by anomalously warm ocean conditions, increasing sea temperatures are predicted to increase algal blooms and consequently DA outbreaks and exposure. Indeed, in 2015, warm ocean conditions resulted in Pseudo-nitzschia blooms that led to the largest outbreak of DA along the North American west coast (McCabe et al., 2016). As DA is transferred through marine food webs via ingestion of Pseudo-nitzschia cells and by consumption of the organisms contaminated with DA (Lefebvre et al., 2002; Lefebvre and Robertson, 2010), DA intoxications in marine animals are closely tied to severity of DA-producing algal blooms (Scholin et al., 2000; Lewitus et al., 2012;

This work was supported by grants from the US National Institutes of Health [R01 ES023043, P51 OD010425, and HD083091].

https://doi.org/10.1124/dmd.117.078485.

S This article has supplemental material available at dmd.aspetjournals.org.
Du et al., 2016). Hence, the increase in DA outbreaks also precipitates a potential increase in public health risks of exposure to DA.

Human DA poisoning affected over 100 individuals in 1987. Three individuals died and others reported signs of DA-related amnesic shellfish poisoning, including gastrointestinal distress, neurologic abnormalities, seizures, and autonomic nervous system dysfunction (Perl et al., 1990; Todd, 1993). Analysis of nine of these cases suggested the toxication was due to consumption of DA-containing mussels at intake levels of 60-290 mg (0.9-4.1 mg/kg) of DA (Perl et al., 1990), but DA concentrations in the affected individuals could not be measured. The acute toxicity of DA has since been extensively studied, and oral acute reference doses and tolerable daily intake (TDI) values of $0.018-0.1 \mathrm{mg} / \mathrm{kg}$ have been proposed (Costa et al., 2010). A TDI of $0.075 \mathrm{mg} / \mathrm{kg}$ orally was suggested based on the no observed adverse effect level (NOAEL) in monkeys following short-term exposure $(0.75$ $(\mathrm{mg} / \mathrm{kg}) /$ day DA orally for 15 days) (Mariën, 1996; Truelove et al., 1997). However, information to establish a chronic TDI for DA is currently not available (Pulido, 2008). Several studies in model species have suggested that chronic low-level DA exposure at asymptomatic doses results in adverse effects, including epigenetic changes and sensitization of animals to the toxicity of DA (Hiolski et al., 2014; Lefebvre et al., 2017). Yet, the underlying mechanisms of these changes and DA toxicokinetics at asymptomatic doses have not been

ABBREVIATIONS: ADAM, advanced dissolution, absorption, and metabolism; AUC, area under the plasma concentration time curve; CL, clearance; DA, domoic acid; ELISA, enzyme-linked immunosorbent assay; $F$, bioavailability; $f_{u}$, fraction unbound; $K_{p}$, tissue to plasma partitioning ratio; LC-MS/MS, liquid chromatography tandem mass spectrometry; LLOQ, lower limit of quantification; PBPK, physiologically based pharmacokinetic; QC, quality control; S.D., Standard Deviation; TDI, tolerable daily intake; $\mathrm{V}_{\mathrm{ss}}$, volume of distribution at steady state. 

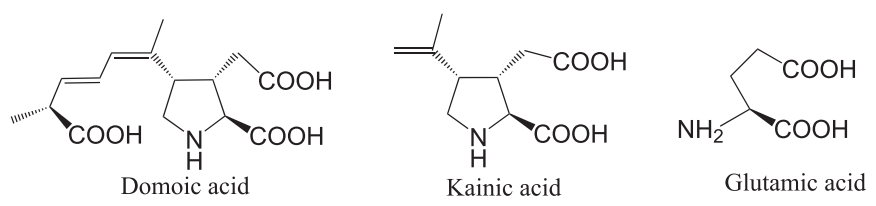

Fig. 1. Structures of domoic acid, kainic acid, and glutamic acid.

characterized. The lack of knowledge of the toxicokinetics of DA is largely due to limited bioanalytical methods to measure DA. LC-MS/MS methods exist for measuring DA in seawater and in contaminated seafood (Wang et al., 2012; Barbaro et al., 2016), but these methods lack the sensitivity needed to quantify DA in biological samples after low level exposure (Frame and Lefebvre, 2013). ELISA can measure DA at concentrations down to $0.4 \mathrm{ng} / \mathrm{ml}$ in biologic specimens (Frame and Lefebvre, 2013), but the ELISA also crossreacts with antibodies against DA, decreasing the usefulness of this assay following chronic exposures (Lefebvre et al., 2012). Therefore, improved LC-MS/MS methods are needed to allow evaluation of DA exposures.

DA is a polar compound $(\log \mathrm{P}=-0.23)$ with four ionized groups, three carboxylic acids $\left(\mathrm{p} K_{\mathrm{a}}\right.$ values $\left.1.85-4.75\right)$ and an amine $\left(\mathrm{p} K_{\mathrm{a}} 10.6\right)$ (Walter et al., 1992). Hence, it is expected to have limited permeability across physiological barriers such as intestinal epithelium, blood-brain barrier, and the placenta. Low permeability of DA in Caco- 2 cells has been shown (Kimura et al., 2011) and the bioavailability of DA appears to be low $(<10 \%)$ based on observed excretion of DA into urine following intravenous and oral doses to monkeys (Truelove and Iverson, 1994; Truelove et al., 1997), and recovery of unchanged DA in feces of rodents after oral dose (Iverson et al., 1990). Distribution of DA to the brain and penetration to the developing fetus in pregnant rodents has also been shown after intravenous doses to rodents (Maucher Fuquay et al., 2012a,b). Yet, knowledge of the overall toxicokinetics and target tissue distribution of DA following exposures similar to those that may occur in humans is lacking.

As human and wildlife exposures to DA are exclusively via oral consumption, the aim of this study was to characterize DA toxicokinetics following oral administration to nonhuman primates at levels of exposure near and at the proposed TDI level, and to establish the key toxicokinetic parameters of DA following intravenous and oral dosing to monkeys. Physiologically based pharmacokinetic (PBPK) models of DA toxicokinetics in monkeys and humans were developed to allow simulation of DA toxicokinetics following different routes of administration after acute and chronic exposure.

\section{Materials and Methods}

Chemicals and Reagents. DA was purchased from BioVectra (Charlottetown, PE, Canada). Certified calibration solution for DA was purchased from National Research Council Canada (Ottawa, ON, Canada). Optima grade water, methanol, acetonitrile, and formic acid used for bioanalytical assays were purchased from Fisher Scientific (Pittsburgh, PA). $\beta$-Glucuronidase from Escherichia coli and ammonium acetate were purchased from Sigma-Aldrich (St. Louis, MO).

Animal Studies. The study was conducted in three healthy adult female cynomolgus monkeys between ages 9.8 and 10.3 years and weighing $5.2 \pm 1.6 \mathrm{~kg}$ (range 3.5-7.2 kg). Animals were housed in the Infant Primate Research Laboratory at the Washington National Primate Research Center. Animals were unsedated for the duration of the study, with unrestricted access to food and water. Animals were fed with Laboratory Diet High Protein Monkey Diet biscuits twice a day, once approximately 2 hours before the DA dose and once approximately 5 hours after the dose of DA. All animal procedure guidelines followed the Animal Welfare Act and the Guide for Care and Use of Laboratory Animals of the National Research Council. All protocols were approved by the University of Washington Institutional Animal Care and Use Committee.
A single intravenous dose of $5 \mu \mathrm{g} / \mathrm{kg}$ DA dissolved in sterile saline was administered. Blood samples were collected from the saphenous vein before treatment (baseline) and 5, 10, 20, 30, and 45 minutes and 1, 1.5, 2, 3, and 4 hours after treatment. Two repeated intravenous dosing studies were conducted in these animals. During the second intravenous dosing study, urine and feces were collected from cage pans after every blood draw during the study period and at 8 , 12, and 24 hours postdose. The DA kinetics were also characterized in these animals following a single oral dose of 0.075 or $0.15 \mathrm{mg} / \mathrm{kg}$ DA. DA oral dose was prepared by dissolving $1 \mathrm{mg} / \mathrm{ml} \mathrm{DA}$ in tap water with $5 \%$ sucrose, and the solution was filtered with a syringe filter $(0.2 \mu \mathrm{M}, 25 \mathrm{~mm})$ before use. The dose was given to animals without restraint. Blood samples were collected at baseline and at 1, 1.5, 2, 3, 5, 8, 12, 16, 24, and 48 hours postdose. Urine was collected from cage pans after every blood draw for 24 hours during the study with $0.075 \mathrm{mg} / \mathrm{kg}$ DA orally. A washout period of at least 2 weeks was given between each exposure.

Blood samples were collected into sodium heparin tubes and centrifuged at 3,000 $\mathrm{g}$ for 15 minutes to isolate plasma for further analysis. Plasma, urine, and feces samples were stored at $-20^{\circ} \mathrm{C}$ until analysis. For all studies, the dosing solutions were analyzed for DA content by LC-MS/MS as described below to confirm DA concentrations.

DA Plasma Protein Binding and Blood-to-Plasma Ratio. The protein binding of DA in plasma was determined by ultracentrifugation using plasma samples from six female cynomolgus monkeys. Three of these monkeys were dosed with $0.15 \mathrm{mg} / \mathrm{kg}$ DA orally, 4-6 hours prior to blood sampling, allowing determination of plasma protein binding in exposed animals at physiologically relevant concentration $(1-10 \mathrm{nM})$. The other three monkeys were unexposed, and the plasma from these animals was spiked with $100 \mathrm{nM}$ DA. Plasma from each animal was aliquoted into six tubes with $100 \mu \mathrm{l}$ plasma in each tube. Three of these plasma samples were incubated at $37^{\circ} \mathrm{C}$ for 90 minutes and, meanwhile, another three samples were ultracentrifuged at $451,268 \mathrm{~g}$ for 90 minutes at $37^{\circ} \mathrm{C}$. After ultracentrifugation, the supernatant was collected and prepared together with incubated plasma samples using the method described below for LC-MS/MS analysis. The unbound fraction in plasma $\left(\mathrm{f}_{\mathrm{u}, \mathrm{p}}\right)$ was determined as DA concentration measured in the supernatant divided by the DA concentration in the incubated plasma samples. The protein binding of DA in human plasma at $100 \mathrm{nM}$ DA was determined similarly by ultracentrifugation using pooled plasma from eight healthy adult subjects.

The blood-to-plasma concentration ratio of DA was measured as previously described (Jing et al., 2017) in fresh blood from six female cynomolgus monkeys. As described above, three monkeys were dosed with DA and blood-to-plasma concentration ratio was measured in the collected fresh blood, with DA distribution reflecting that obtained after exposure to DA. Fresh blood from the other three unexposed monkeys was spiked with DA to $100 \mathrm{nM}$ final concentration in whole blood. Samples were mixed, aliquoted into four $700 \mu \mathrm{l}$ aliquots, and incubated at $37^{\circ} \mathrm{C}$ for up to 2 hours with aliquots removed at 10 and 30 minutes and 1 and 2 hours. At each time point, $60 \mu$ l of blood in triplicate was removed, and protein was precipitated with $60 \mu \mathrm{l}$ methanol. The remaining $500 \mu \mathrm{l}$ of blood was centrifuged at $1,000 \mathrm{~g}$ for 10 minutes at $4^{\circ} \mathrm{C}$ to pellet red blood cells and isolate plasma. After centrifugation, $60 \mu \mathrm{l}$ of plasma was added to $60 \mu \mathrm{l}$ of methanol (in triplicate aliquots), and the samples were prepared as described below and analyzed by LC-MS/MS. The blood-to-plasma concentration ratio of DA (100 nM) was measured using identical methods in fresh human blood.

Analysis of DA Concentrations in Biological Samples by LC-MS/MS. For DA measurements in plasma, $60 \mu \mathrm{l}$ of methanol was added to $60 \mu \mathrm{l}$ plasma, and the samples were centrifuged at $16,100 \mathrm{~g}$ for 40 minutes, set at $4^{\circ} \mathrm{C}$ for 30 minutes, and centrifuged again at $16,100 \mathrm{~g}$ for 30 minutes. The supernatant was collected for analysis. For plasma samples that had concentrations beyond $40 \mathrm{ng} / \mathrm{ml}$ based on initial analysis, the supernatant was diluted twofold with water for analysis. For DA measurements in urine, $60 \mu \mathrm{l}$ of methanol was added to $60 \mu \mathrm{l}$ of urine, the samples were centrifuged at $16,100 \mathrm{~g}$ for 20 minutes, and supernatant was collected and diluted 10-fold with water for analysis. For urine samples that had DA concentrations above the range of standard curves after this dilution, the supernatant was collected and diluted 50-fold with water for analysis. Samples that had undetectable/unquantifiable concentrations with 10-fold dilution were prepared with addition of $60 \mu \mathrm{l}$ of methanol to $60 \mu \mathrm{l}$ urine. These samples were analyzed by LC-MS/MS without further dilution. Standard curves were prepared the same way as the urine samples. For DA measurements in feces, $1 \mathrm{~g}$ of feces was first homogenized with $3 \mathrm{ml}$ of water using Omni tissue homogenizer 
TABLE 1

Summary of input parameter values for DA PBPK model in monkeys

\begin{tabular}{|c|c|c|}
\hline Parameters & Input Values & Reference/Comment \\
\hline Molecular weight $(\mathrm{g} / \mathrm{mol})$ & 311.33 & PubChem \\
\hline $\log \mathrm{P}_{\text {o:w }}$ & -0.23 & Drug bank \\
\hline Compound type & Ampholyte & \\
\hline $\mathrm{p} K_{\mathrm{a}} 1$ & 4.75 & Walter et al. (1992) \\
\hline pKa 2 & 10.6 & Walter et al. (1992) \\
\hline Blood-to-plasma ratio & 0.615 & Simcyp default value \\
\hline $\mathrm{fu}_{\mathrm{p}}$ & 1.0 & Measured \\
\hline Absorption & ADAM & \\
\hline $\mathrm{F}_{\mathrm{a}}$ & 0.07 & Predicted \\
\hline$P_{\text {eff }}\left(10^{-4} \mathrm{~cm} / \mathrm{s}\right)$ & 0.018 & Predicted \\
\hline$f_{u, g u t}$ & 1 & Predicted \\
\hline Distribution & Full PBPK model & \\
\hline $\mathrm{V}_{\mathrm{ss}}(1 / \mathrm{kg})$ & 0.15 & Measured \\
\hline$K_{\mathrm{p}}-$ brain & 0.066 & Maucher-Fuquay et al. (2012a) \\
\hline$K_{\mathrm{p}}-$ kidney & 0.46 & Funk et al. (2014) \\
\hline$K_{\mathrm{p}}-$ liver & 0.13 & Funk et al. (2014) \\
\hline$K_{\mathrm{p}}-$ heart & 0.05 & Funk et al. (2014) \\
\hline$K_{\mathrm{p}}-$ adipose & 0.04 & Predicted \\
\hline$K_{\mathrm{p}}-$ bone & 0.13 & Predicted \\
\hline$K_{\mathrm{p}}-$ gut & 0.17 & Predicted \\
\hline$K_{\mathrm{p}}-$ lung & 0.18 & Predicted \\
\hline$K_{\mathrm{p}}-$ muscle & 0.17 & Predicted \\
\hline$K_{\mathrm{p}}-$ skin & 0.14 & Predicted \\
\hline$K_{\mathrm{p}}-$ spleen & 0.17 & Predicted \\
\hline$K_{\mathrm{p}}$ scalar & 0.23 & Assigned \\
\hline \multicolumn{3}{|l|}{ Elimination } \\
\hline Renal clearance $[(\mathrm{ml} / \mathrm{min}) / \mathrm{kg}]$ & 0.98 & Measured \\
\hline $\mathrm{CL}_{\text {int }}(\mathrm{Hep})(\mu \mathrm{l} / \mathrm{min}) / 10^{6}$ cells $^{a}$ & 0.48 & $\begin{array}{l}\text { Assigned (back-calculated from } \\
\text { nonrenal clearance) }\end{array}$ \\
\hline
\end{tabular}

${ }^{a}$ This value is used to reflect biliary secretion of DA in hepatocytes based on predicted in vivo biliary clearance of $65(\mathrm{ml} / \mathrm{h}) / \mathrm{kg}$. The model cannot differentiate possible metabolism and biliary secretion, and this value should be considered as clearance via other pathways.

(Omni International, Kennesaw, GA). After homogenization, $60 \mu 1$ of methanol was added to $60 \mu \mathrm{l}$ of sample, and the mixture was centrifuged for 20 minutes at $16,100 \mathrm{~g}$. The supernatant was collected for LC-MS/MS analysis.

Standard curves were prepared using blank monkey plasma spiked with DA at concentrations of $0.6-40 \mathrm{ng} / \mathrm{ml}(2-128 \mathrm{nM})$, blank monkey urine spiked to concentrations $16-996 \mathrm{ng} / \mathrm{ml}(50-3200 \mathrm{nM})$ of DA, and blank monkey feces spiked to concentrations $6-103 \mathrm{ng} / \mathrm{ml}(20-332 \mathrm{nM})$ of DA. A separate plasma standard curve at 6-199 $\mathrm{ng} / \mathrm{ml}(20-640 \mathrm{nM})$ of DA was prepared for samples exceeding concentrations of $40 \mathrm{ng} / \mathrm{ml}$. These samples were diluted as described above for high concentration samples. In addition, standard curves for urine analysis were prepared at concentrations of $124-3985 \mathrm{ng} / \mathrm{ml}(400-12,800 \mathrm{nM})$ for 1:50 dilution and $0.6-40 \mathrm{ng} / \mathrm{ml}(2-128 \mathrm{nM})$ for undiluted samples. All standard curves had $\geq 6$ concentrations of DA. Low, middle and high concentration quality control (QC) samples that were close to the lowest, middle, and highest concentration within the standard curve were extracted along with standard curves and also included in all analyses. Low, middle, and high QC samples were at DA concentrations of $0.9,7$, and $30 \mathrm{ng} / \mathrm{ml}(3,24$, and $96 \mathrm{nM})$ for plasma measurements; 16, 156, and $623 \mathrm{ng} / \mathrm{ml}(50,500$, and $2000 \mathrm{nM})$ for urine measurements; and 6, 31, and $62 \mathrm{ng} / \mathrm{ml}(20,100$, and $200 \mathrm{nM})$ for feces measurements. Uniform weighing was used for all standard curves.

To determine the potential metabolic conjugation of DA in vivo, urine samples were analyzed with and without $\beta$-glucuronidase hydrolysis treatment. Briefly, each urine sample was divided into three $200 \mu \mathrm{l}$ aliquots. Ammonium acetate $(46.1 \mu \mathrm{l} ; 1 \mathrm{M})$ and $40 \mathrm{U} \beta$-glucuronidase $(6.1 \mu \mathrm{l}$ of $6.5 \mathrm{U} / \mu \mathrm{l}$ in $100 \mathrm{mM}$ ammonium acetate) were added to $200 \mu \mathrm{l}$ urine and incubated at $37^{\circ} \mathrm{C}$ for 24 hours. To compare with the samples treated with $\beta$-glucuronidase, $52.2 \mu \mathrm{l}$ ammonium acetate $(1 \mathrm{M})$ was added to an additional $200 \mu \mathrm{l}$ aliquot of the urine sample and incubated at $37^{\circ} \mathrm{C}$ for 24 hours. To confirm the stability of DA in this assay, $52.2 \mu 1$ ammonium acetate $(1 \mathrm{M})$ was added to another $200 \mu \mathrm{l}$ urine sample and stored at $-20^{\circ} \mathrm{C}$ until analysis. After 24 hours, samples were prepared as described above for analysis by LC-MS/MS

DA concentrations in plasma samples were measured by LC-MS/MS, using AB Sciex 5500 qTrap Q-LIT mass spectrometer (AB Sciex, Foster City, CA) equipped with an Agilent 1290 UHPLC (Agilent, Santa Clara, CA) and a Synergi Hydro-RP $100 \AA$ LC Column $(2.5 \mu \mathrm{m}, 50 \times 2 \mathrm{~mm}$; Phenomenex, Torrance, CA). Compound-dependent MS parameters used for detection of DA were collision energy 26 , collision cell exit potential 10, declustering potential 100 , and entrance potential 10 . Gradient elution with a flow rate of $0.5 \mathrm{ml} / \mathrm{min}$ using (A) water with $0.1 \%$ formic acid and (B) $95 \%$ acetonitrile with $5 \%$ water and $0.1 \%$ formic acid was used. The gradient was from an initial 95\% A for 1 minute to $0 \%$ A over 3 minutes and then to $95 \%$ A for 3 minutes. Analytes were detected using positive ion electrospray ionization mode. MS/MS transition monitored for DA was $\mathrm{m} / \mathrm{z} 312.2>266$. DA in the dosing solutions and in urine and feces samples was measured by LC-MS/MS, using AB Sciex 4500 mass spectrometer (AB Sciex) equipped with a Shimadzu UFLC XR DGU-20A5 (Shimadzu Scientific Instruments, Columbia, MD) and a Synergi Hydro-RP $100 \AA \AA$ LC Column $(2.5 \mu \mathrm{m}, 50 \times 2 \mathrm{~mm}$; Phenomenex $)$. Compound-dependent mass spectrometer parameters used for detection of DA were collision energy 20 , collision cell exit potential 10, declustering potential 51, and entrance potential 10. Gradient elution and MS/MS transitions monitored for DA were as described above. Samples were kept in the autosampler at $4^{\circ} \mathrm{C}$ and $10 \mu \mathrm{l}$ of sample was injected for analysis.

Pharmacokinetic Analysis. Pharmacokinetic parameters including area under the plasma concentration time curve (AUC), volume of distribution at steady state $\left(\mathrm{V}_{\mathrm{ss}}\right)$, systemic clearance $(\mathrm{CL})$, half-life $\left(\mathrm{t}_{1 / 2}\right)$ maximum plasma concentration $\left(C_{\max }\right)$, time to reach $C_{\max }$, and linear terminal slope were estimated by standard noncompartmental analysis using Phoenix (St. Louis, MO). The geometric mean values are reported for all pharmacokinetic parameters except $C_{\max }$ which is reported as arithmetic mean. AUC was calculated by the linear log trapezoidal method for iv dosing data and linear trapezoidal method for oral dosing data and extrapolated to infinity using the determined linear terminal slope (from last five to seven time points in intravenous studies and three to five time points in oral studies) and last observed plasma concentration. Absolute bioavailability (F) was calculated using equation:

$$
\mathrm{F}=\frac{A U C_{\text {oral }}}{A U C_{i . v .}} \times \frac{\text { Dose }_{\text {i.v. }}}{\text { Dose }_{\text {oral }}}
$$


Renal clearance $\left(\mathrm{CL}_{\mathrm{R}}\right)$ after intravenous and oral dose was obtained using equation:

$$
\mathrm{CL}_{\mathrm{R}}=\frac{A_{e, 0-24}}{A U C_{0-24}}
$$

in which $\mathrm{A}_{\mathrm{e}, 0-24}$ is the amount of DA excreted in urine over 24 hours after intravenous or oral dose and the $\mathrm{AUC}_{0-24}$ is the $\mathrm{AUC}$ over the 24-hour interval after intravenous or oral dose.

Creatinine clearance $\left(\mathrm{CL}_{\mathrm{cr}}\right)$ in the monkeys was calculated using equation:

$$
\mathrm{CL}_{\mathrm{cr}}=\frac{\frac{d A_{e}}{d t}}{C}
$$

in which $\mathrm{A}_{\mathrm{e}}$ is the amount of creatinine excreted in urine over a 4-hour interval $(\mathrm{d} t)$ and $\mathrm{C}$ is the concentration of creatinine measured in plasma. Blood and urine samples for creatinine clearance measurement were collected before the DA intravenous dose. Blood and urine creatinine concentrations were measured by clinical assays at Department of Laboratory Medicine, University of Washington Medical Center.

PBPK Model of DA disposition in Monkeys. A PBPK model of DA was constructed as a full PBPK model using Simcyp Monkey version 16 (Certara, Sheffield, UK). This model is based on cynomolgus monkey physiology without any sex differences in physiological parameters, i.e., the simulation results are independent of sex. The absorption kinetics of DA were simulated with advanced dissolution, absorption, and metabolism (ADAM) model. In brief, the fraction absorbed $\left(\mathrm{F}_{\mathrm{a}}\right)$ and $\mathrm{F}$ were predicted using mechanistic $\mathrm{P}_{\text {eff }}$ model with scaling factor of 0.45 applied to the $\mathrm{P}_{\text {eff }}$ predicted from physicochemical parameters for each part of the intestine, to account for the multiple charges in DA molecule that could not be included in the prediction. For DA distribution, a full PBPK model was used. A $K_{\mathrm{p}}$ value for brain was assigned according to the reported $\mathrm{AUC}_{\text {brain }} /$ $\mathrm{AUC}_{\text {plasma }}$ ratio in pregnant rats (Maucher Fuquay et al., 2012a). For kidney, liver, and heart, $K_{\mathrm{p}}$ values were estimated based on the reported concentrations in mice (Funk et al., 2014). $K_{\mathrm{p}}$ values for the rest of the organs were independently predicted in Simcyp using the method described by Rodgers and Rowland (2006) with application of a $K_{\mathrm{p}}$ scalar $(0.23$, Table 1$)$ to obtain measured $\mathrm{V}_{\mathrm{ss}}$ that was consistent with the intravenous study. The elimination of DA was characterized using the measured systemic clearance after intravenous dosing [124 $(\mathrm{ml} / \mathrm{h}) / \mathrm{kg}$, range 87-218 (ml/h)/kg]. The geometric mean renal clearance based on all the animals in all the study days $[59(\mathrm{ml} / \mathrm{h}) / \mathrm{kg}$, range $21-152(\mathrm{ml} / \mathrm{h}) / \mathrm{kg}]$ was used in the model. The rest of the systemic clearance $[65(\mathrm{ml} / \mathrm{h}) / \mathrm{kg}]$ was assigned as biliary clearance based on lack of observed metabolism of DA, and the detection of unchanged DA in the feces of monkeys after intravenous dosing and in bile of marine mammals. It is important to note that it is possible DA is also metabolized, but as the current data cannot differentiate between biliary clearance and metabolism either by gut microbiome or by the monkey enzymes, only biliary clearance was included to reflect clearance by other pathways. The biliary clearance per hepatocyte was back-calculated using retrograde scaling. The percentage available for reabsorption was set as $100 \%$, and a sensitivity analysis was conducted for values between $0 \%$ and $100 \%$. The model was found to be insensitive to this value. The details of the model input parameters are listed in Table 1, and representative model output files are included as Supplemental Material. The model acceptance criterion was set as $\leq 2-$ fold difference between the mean simulated values and observed mean values for AUC. The predicted variability in DA disposition was simulated using the range of observed renal clearance values in this study, as the Simcyp monkey model does not allow simulation of population variability in renal or biliary clearance.

The DA PBPK model was tested by simulating DA disposition in monkeys following intravenous and oral dosing and comparing the simulated results with the in-house toxicokinetic data and the reported data from literature following higher doses of DA to monkeys. In all the simulations, renal clearance values were scaled to the reported body weights of the monkeys in the observed studies. The observed concentration-time profiles from prior publications reporting DA plasma

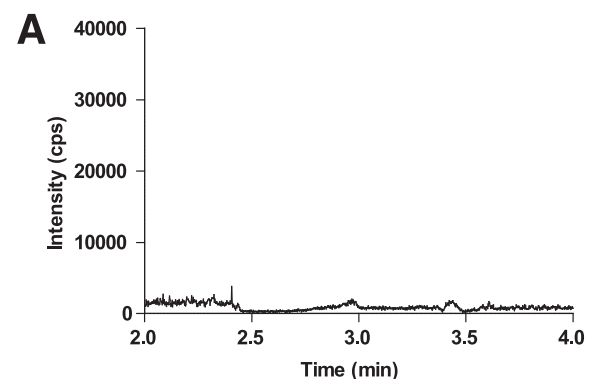

B
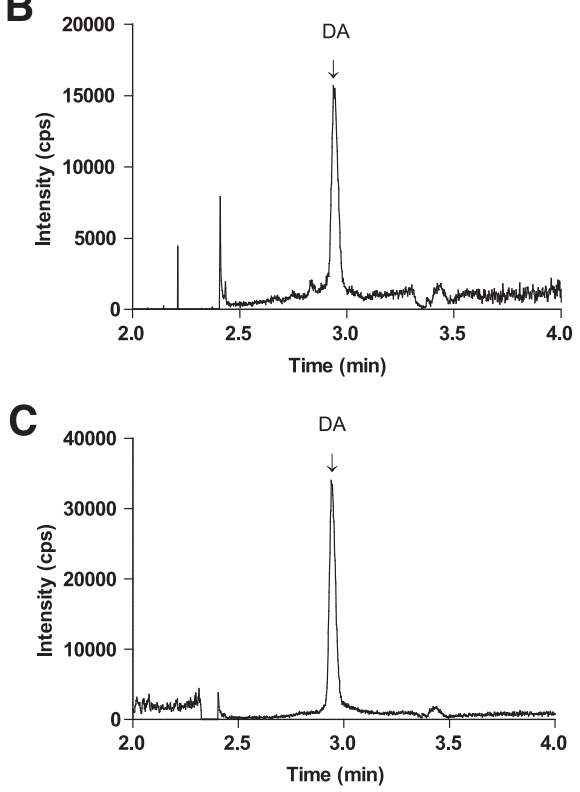

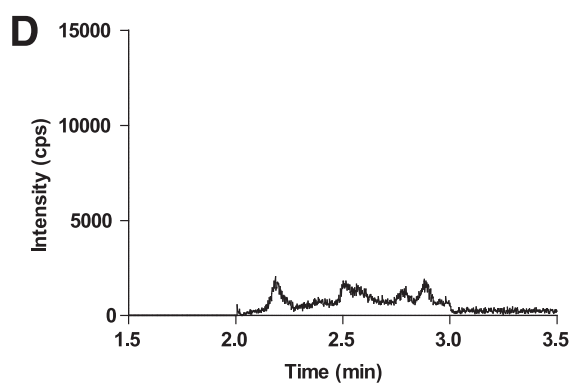

E
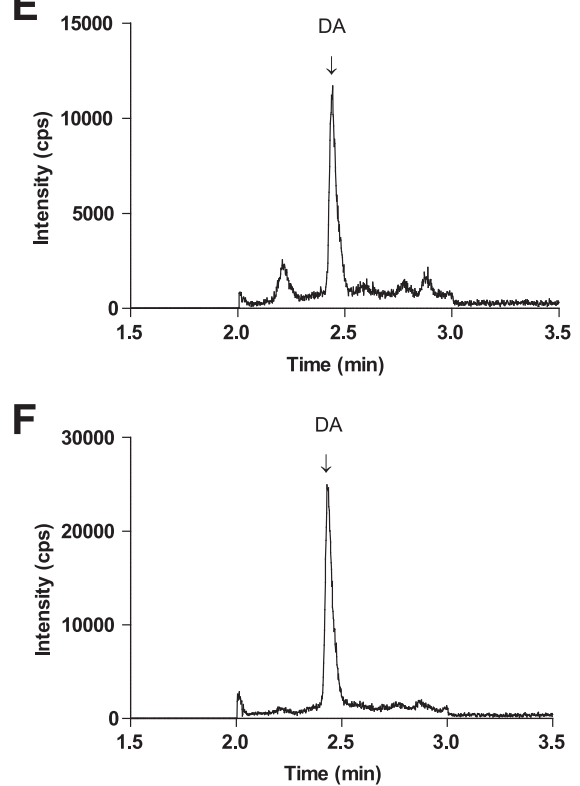

Fig. 2. Detection of domoic acid (DA) by LC-MS/MS in monkey plasma and urine samples. (A) Blank plasma (B) Plasma sample spiked with $0.6 \mathrm{ng} / \mathrm{ml}(2.0 \mathrm{nM}) \mathrm{DA}$, (C) Detection of DA in a plasma sample collected 24 hours after dosing with $0.15 \mathrm{mg} / \mathrm{kg}$ DA orally. The detected concentration of DA is $2.0 \mathrm{ng} / \mathrm{ml}(6.3 \mathrm{nM})$. (D) Blank urine. (E) Detection of DA in a urine sample spiked with $1.6 \mathrm{ng} / \mathrm{ml}(5.0 \mathrm{nM})$ DA. (F) Detection of DA in a urine sample collected 24 hours after a $0.15 \mathrm{mg} / \mathrm{kg}$ oral DA dose. The concentration of DA is $3.7 \mathrm{ng} / \mathrm{ml}(11.8 \mathrm{nM})$. Samples were prepared and analyzed as described in Materials and Methods. 


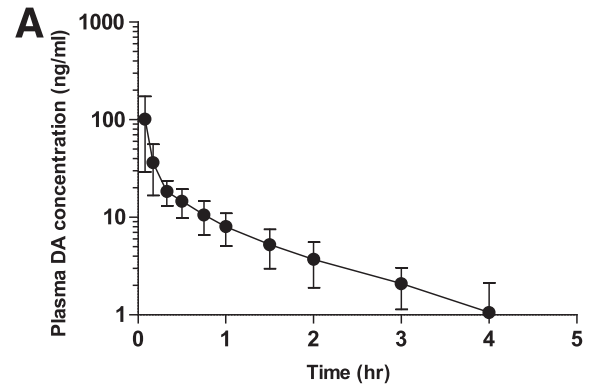

\section{C}

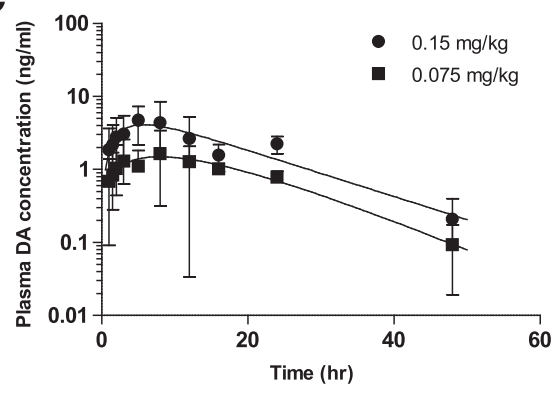

B

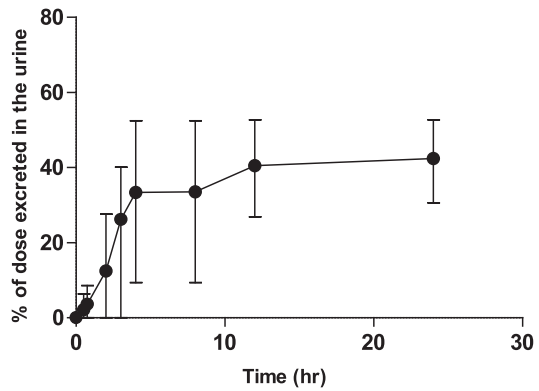

D

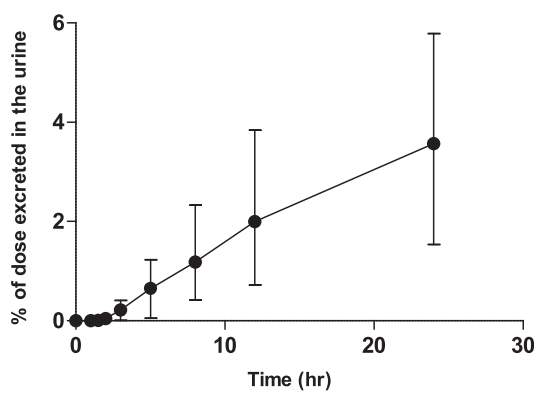

Fig. 3. Toxicokinetics of DA in monkeys $(n=3)$ following intravenous and oral administration. (A) Mean plasma concentration-time profile of DA following a single intravenous dose of $5 \mu \mathrm{g} / \mathrm{kg}$ DA. Each data point represents the mean and S.D. of the plasma concentrations measured in two different studies in three animals. (B) Time course of DA excretion into urine following intravenous dosing. The percentage of the intravenous dose of DA $(5 \mu \mathrm{g} / \mathrm{kg}$ ) excreted in the urine as a function of time is shown. Each data point is the mean and S.D. of three animals. (C) Mean plasma concentration versus time curves of DA following a single oral dose of 0.075 and $0.15 \mathrm{mg} / \mathrm{kg}$ DA. Each data point represents the mean and S.D. of three monkeys. (D) Time course of DA excretion into urine following oral dose of $0.075 \mathrm{mg} / \mathrm{kg}$ DA. The percentage of oral DA dose excreted in the urine as a function of time is shown as mean and S.D. of three animals. concentrations in cynomolgus monkeys (Truelove and Iverson, 1994; Truelove et al., 1997) were digitized using Plot Digitizer software (http://plotdigitizer. sourceforge.net). For each study, Simcyp species representative individuals were simulated at fed condition using observed range of renal clearances to represent population variability. Sensitivity analysis was done on biliary clearance ranging from 0.23 to $0.53(\mu \mathrm{l} / \mathrm{min}) /$ million cells by comparing first-order absorption kinetics and ADAM model and fed and fasted conditions. With the exception of fed versus fasted conditions, the model was found to be sensitive to all of the above parameters.

PBPK Model of DA disposition in Humans. A PBPK model of DA disposition in humans was constructed as a full PBPK model using Simcyp version 16 (Certara). The model was based on the developed cynomolgus monkey model using body weight-scaled physiology, renal clearance, and biliary clearance. The absorption kinetics of DA were simulated with human ADAM model. The predicted permeability values corresponded to those used in the monkey model with predicted mechanistic $\mathrm{P}_{\text {eff }}$ values and the same scaling factor of 0.45 . For DA distribution, the $K_{\mathrm{p}}$ values applied to the monkey tissues were also applied in the human model. Both biliary secretion and renal clearance were incorporated in the model. For biliary clearance, the same $\mathrm{CL}_{\mathrm{int}}$ value in microliters per minute per $10^{6}$ cells was used in the human model and the monkey model. Human renal clearance value was set as $38 \%$ of GFR based on the data obtained in the monkeys. No model acceptance criterion was set, as no data exist of DA disposition in humans. DA disposition in humans was simulated in 100 healthy individuals (age: $18-65$, average body weight: $80.7 \mathrm{~kg}, 34 \%$ female) using the TDI dose $(0.075 \mathrm{mg} / \mathrm{kg})$ and the estimated dose range $(0.9-4 \mathrm{mg} / \mathrm{kg})$ in the Canadian poisoning event. A representative model output file is included as Supplemental Material.

\section{Results}

Development of a Sensitive and Specific LC-MS/MS Method to Measure DA in Biological Samples. To measure DA in biological samples including plasma and urine following intravenous and oral administration at a dose level near or at the proposed TDI, a sensitive LC-MS/MS method was developed and validated. DA was detected in monkey plasma and urine using this method and the chromatograms of DA in the biological matrices are shown in Fig. 2. The assay was validated according to the published guidelines for bioanalytical method validation (Shah et al., 2000; Viswanathan et al., 2007). The lower limits of quantification (LLOQ) in plasma and urine were $0.6 \mathrm{ng} / \mathrm{ml}(2 \mathrm{nM})$ and $1.6 \mathrm{ng} / \mathrm{ml}(5 \mathrm{nM})$, respectively, based on signal-to-noise ratio $>9$ and interday $\mathrm{CV} \%<15 \%$. The accuracy and CV\% values of QC samples were $<15 \%$ at all concentrations. The assay was determined sensitive enough to measure DA concentrations in plasma following oral exposures at the proposed TDI level of DA.

Toxicokinetics of DA Following Single Intravenous and Oral Doses. The toxicokinetics of DA following intravenous and oral administration was studied in three female monkeys. Following an

TABLE 2

Observed and predicted toxicokinetic parameters of DA in monkeys after single intravenous doses

Observed values are reported as geometric mean \pm S.D. The predicted population representative values simulated using the PBPK model are shown together with the predicted range of values included in parentheses.

\begin{tabular}{lcccc}
\hline \multicolumn{1}{c}{ PK Parameter } & $\begin{array}{c}\text { Observed } 5 \mu \mathrm{g} / \mathrm{kg} \\
\text { intravenously }\end{array}$ & $\begin{array}{c}\text { Predicted } 5 \mu \mathrm{g} / \mathrm{kg} \\
\text { intravenously }\end{array}$ & $\begin{array}{c}\text { Observed } 50 \mu \mathrm{g} / \mathrm{kg}^{a} \\
\text { intravenously }\end{array}$ & $\begin{array}{c}\text { Predicted } 50 \mu \mathrm{g} / \mathrm{kg} \\
\text { intravenously }\end{array}$ \\
\hline $\mathrm{AUC}_{0-\infty}[(\mathrm{h} \cdot \mathrm{ng}) / \mathrm{ml}]$ & $40 \pm 24$ & $40(23-58)$ & $700 \pm 334$ & $403(230-578)$ \\
$\mathrm{CL}[(\mathrm{ml} / \mathrm{h}) / \mathrm{kg}]$ & $124 \pm 71$ & $124(87-218)$ & $73 \pm 33$ & $124(87-218)$ \\
$\mathrm{CL}_{\mathrm{R}}[(\mathrm{ml} / \mathrm{h}) / \mathrm{kg}]$ & $36 \pm 30$ & $59(21-152)$ & $56 \pm 35$ & $59(21-152)$ \\
$t_{1 / 2}(\mathrm{hours})$ & $1.2 \pm 1.1$ & $0.8(0.5-1.2)$ & $1.7 \pm 1.0$ & $0.8(0.5-1.2)$ \\
$\mathrm{V}_{\mathrm{ss}}(\mathrm{ml} / \mathrm{kg})$ & $131 \pm 71$ & 149 & $165 \pm 17$ & 149 \\
\hline
\end{tabular}

${ }^{a}$ Data from Truelove and Iverson.(1994). 
TABLE 3

Observed and predicted toxicokinetic parameters of DA in monkeys after single oral doses

Observed values are reported as geometric mean \pm S.D except for $C_{\max }$ which is the arithmetic mean and S.D. The predicted population representative value simulated using the PBPK model is shown together with the predicted range of values included in parentheses.

\begin{tabular}{lcccc}
\hline \multicolumn{1}{c}{ PK Parameter } & Observed $0.075 \mu \mathrm{g} / \mathrm{kg}$ oral & Predicted $0.075 \mu \mathrm{g} / \mathrm{kg}$ oral & Observed $0.15 \mu \mathrm{g} / \mathrm{kg}$ oral & Predicted $0.15 \mu \mathrm{g} / \mathrm{kg}$ oral \\
\hline $\mathrm{AUC}_{0-\infty}[(\mathrm{h} \cdot \mathrm{ng}) / \mathrm{ml}]$ & $39 \pm 14$ & $45(25-66)$ & $93 \pm 45$ & $90(51-132)$ \\
$C_{\max }(\mathrm{ng} / \mathrm{ml})$ & $1.9 \pm 1.5$ & $4.4(2.8-5.7)$ & $5.3 \pm 3.4$ & $8.8(5.6-11.5)$ \\
$t_{1 / 2}$ (hours) & $11.3 \pm 2.4$ & $9.3(9.1-9.5)$ & $9.8 \pm 5.9$ & $9.3(9.1-9.5)$ \\
$\mathrm{F}(\%)$ & $6 \pm 4$ & 7.5 & $7 \pm 5$ & 7.5 \\
\hline
\end{tabular}

intravenous dose of $5 \mu \mathrm{g} / \mathrm{kg}$ DA, DA had a systemic clearance of $124 \pm$ $71(\mathrm{ml} / \mathrm{h}) / \mathrm{kg}(n=6)$ and a short elimination half-life of $1.2 \pm 1.1$ hours (Fig. 3A; Table 2). On average, $42 \% \pm 11 \%(n=3)$ of the DA dose was recovered in urine over 24 hours after the intravenous dose. Based on urinary excretion (Fig. 3B), the renal clearance of DA in these animals was $36 \pm 30(\mathrm{ml} / \mathrm{h}) / \mathrm{kg}$, which is $29 \%$ of the mean systemic clearance and $23 \%$ of the creatinine clearance $[155 \pm 55(\mathrm{ml} / \mathrm{h}) / \mathrm{kg}]$ in these monkeys. This suggests significant reabsorption of DA in the kidney, and potential other elimination routes of DA including biliary secretion. In accordance with some biliary secretion of DA, DA was also detected
A
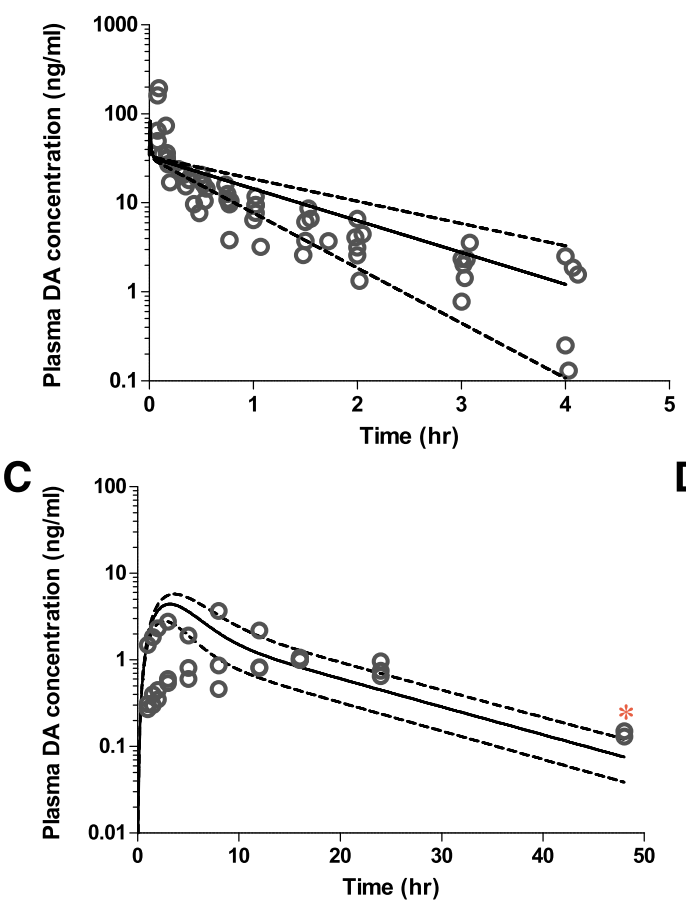

B
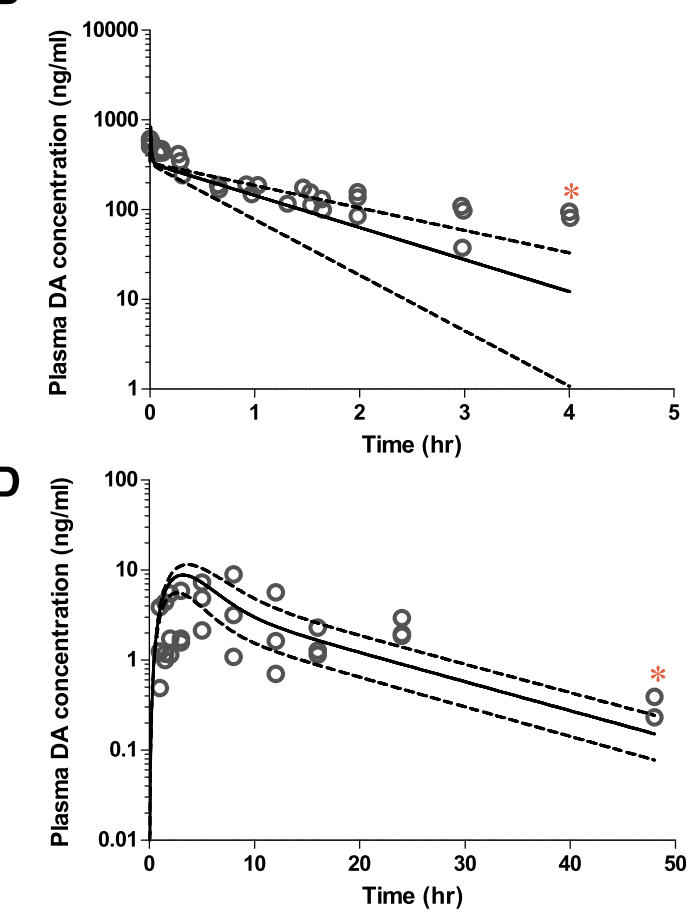

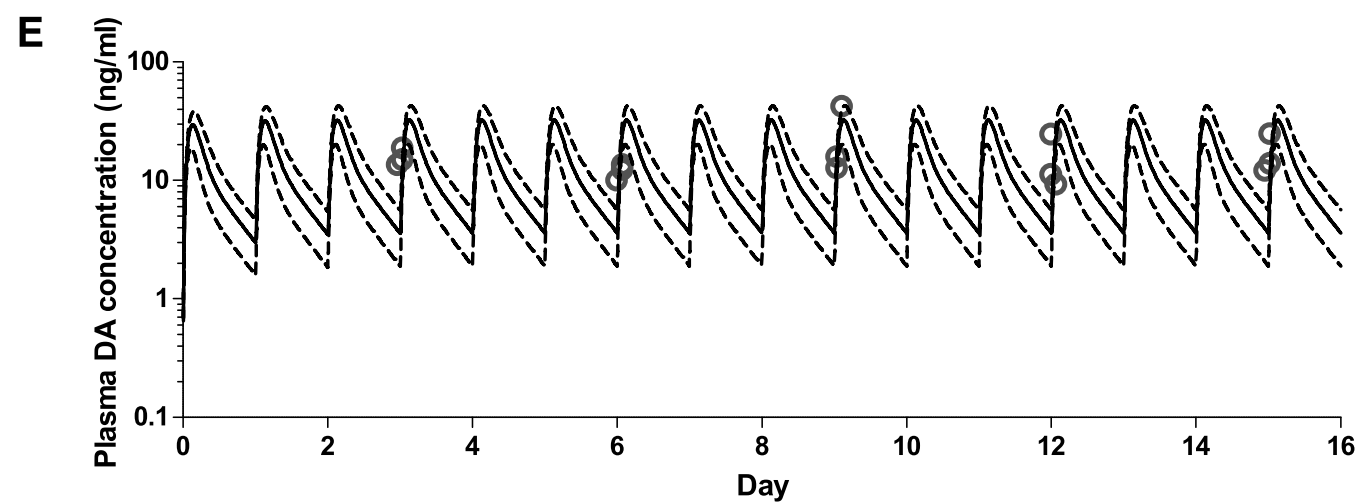

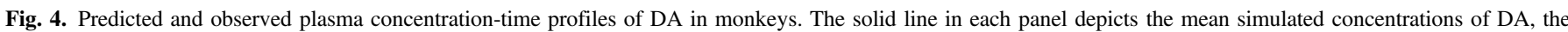

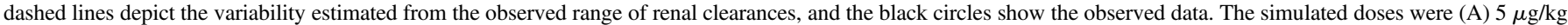

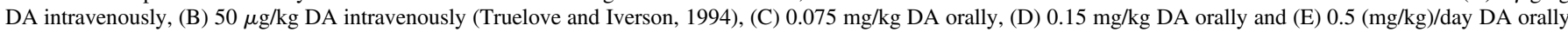

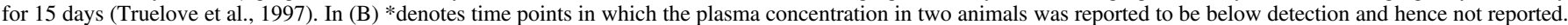
In (C) and (D) *denotes a time point in which DA concentration in one animal was below detection limit and hence data for this animal are not shown. 
A
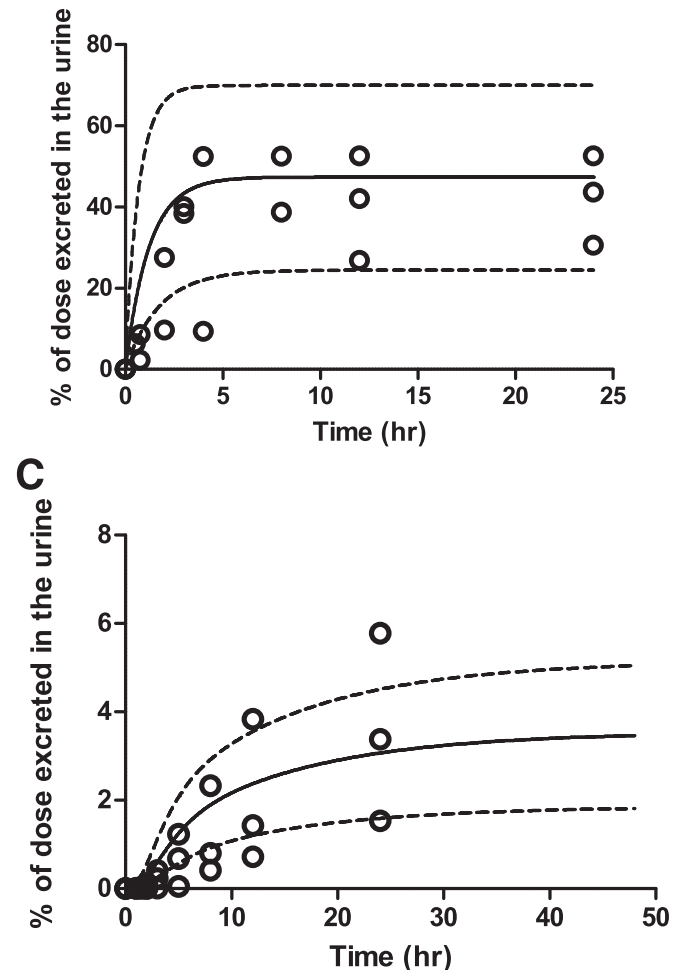

B

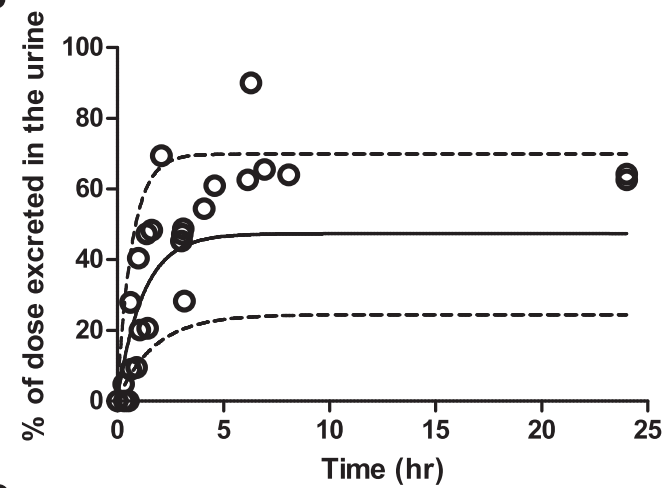

D

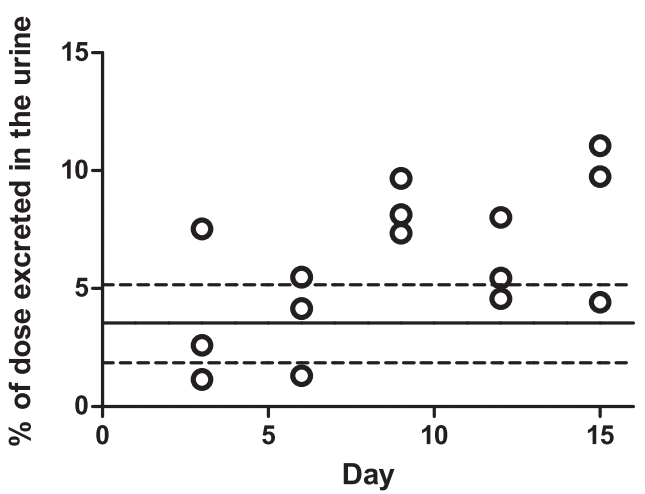

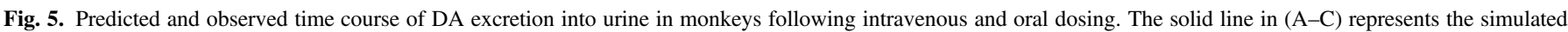

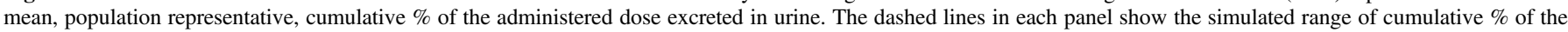

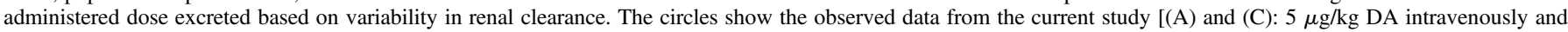

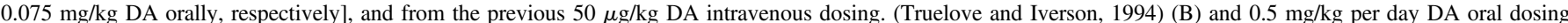

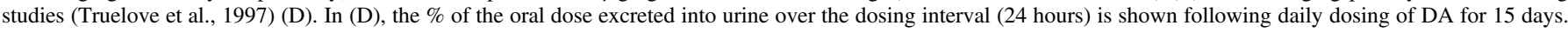

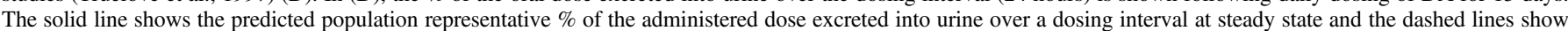

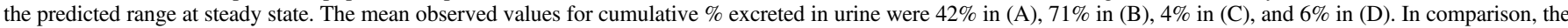
simulated $\%$ excreted in urine were $47 \%$ in (A), $47 \%$ in (B), $3.5 \%$ in (C), and $3.5 \%$ in (D).

in feces after intravenous dosing at small and variable amounts (data not shown), and the highest DA concentration in feces was $72 \mathrm{ng} / \mathrm{g}$ at 0.5 hours post-intravenous dose. Based on DA detection in feces, the maximum total amount of DA eliminated in 24-hour feces was calculated as $5 \%$ of the intravenous DA dose. Treatment of urine with $\beta$-glucuronidase to test potential glucuronidation of DA in vivo did not result in an increase in DA concentration (data not shown).

Administration of single oral doses of DA to the same monkeys at 0.075 and $0.15 \mathrm{mg} / \mathrm{kg}$ showed flip-flop kinetics with an absorption rate constant smaller than the elimination rate constant (Fig. 3C). Following oral administration of $0.075 \mathrm{mg} / \mathrm{kg}$ DA (proposed TDI), maximum DA concentration of $1.9 \pm 1.5 \mathrm{ng} / \mathrm{ml}$ was reached at approximately $13 \pm$ 5 hours postdose. A maximum DA concentration of $5.3 \pm 3.4 \mathrm{ng} / \mathrm{ml}$ was reached at $6 \pm 2$ hours after $0.15 \mathrm{mg} / \mathrm{kg}$ oral dose of DA (twofold of proposed TDI). The terminal half-life of DA was $11.3 \pm 2.4$ and $9.8 \pm$ 5.9 hours following oral dosing of 0.075 and $0.15 \mathrm{mg} / \mathrm{kg} \mathrm{DA}$, respectively (Table 3 ). Based on the pharmacokinetic analysis, the eightfold longer half-life after oral dosing when compared to intravenous dosing indicated flip-flop kinetics with elimination rate constant $(k)$ of $0.5 \pm 0.2$ hour $^{-1}$ and absorption rate constants $\left(k_{\mathrm{a}}\right)$ of $0.06 \pm 0.01$ and $0.07 \pm 0.03$ hour $^{-1}$ following 0.075 and $0.15 \mathrm{mg} / \mathrm{kg}$ oral doses, respectively. The oral clearances of DA were $2.0 \pm 0.7$ and $1.6 \pm 0.9$ $(1 / \mathrm{h}) / \mathrm{kg}$ after single oral doses of 0.075 and $0.15 \mathrm{mg} / \mathrm{kg}$ DA, respectively. Based on the intravenous and oral dosing data, the absolute oral bioavailability of DA was calculated to be $6 \% \pm 4 \%$ and $7 \% \pm 5 \%$ after single doses of 0.075 and $0.15 \mathrm{mg} / \mathrm{kg} \mathrm{DA}$, respectively. After oral administration of $0.075 \mathrm{mg} / \mathrm{kg}$ DA, $4 \% \pm 2 \%$ of the DA dose was recovered in urine over 24 hours (Fig. 3D). The renal clearance of DA measured after oral dosing was $96 \pm 47(\mathrm{ml} / \mathrm{h}) / \mathrm{kg}$, which was $77 \%$ of the systemic clearance of DA after intravenous dosing [124 $\pm 71(\mathrm{ml} / \mathrm{h}) /$ $\mathrm{kg}]$ and $62 \%$ of the creatinine clearance $[155 \pm 55(\mathrm{ml} / \mathrm{h}) / \mathrm{kg}]$ in these monkeys.

Simulation of DA Disposition in Monkeys Using PBPK Modeling. A PBPK model of DA disposition in monkeys was developed based on obtained experimental and literature data. To develop the PBPK model, the unbound fraction of DA in plasma and the blood-to-plasma concentration ratio of DA were measured. No binding of DA was observed in monkey or human plasma and the unbound fraction was determined to be 1.0. Blood-to-plasma ratio of DA measured in blood from monkeys dosed with DA was $0.59 \pm 0.05$. The average hematocrit value for these monkeys was $0.44 \pm 0.05$. The blood to plasma ratio measured in spiked blood samples at $100 \mathrm{nM}$ showed consistent values during the time of incubation with average value of $0.56 \pm 0.02$. The average hematocrit value for these monkeys was 0.45 \pm 0.01 . Blood-to-plasma ratio of DA measured in human blood showed consistent values during the incubation with average value of $0.51 \pm$ 0.01 . These results indicated no partitioning of DA into red blood cells. As the blood-to-plasma ratio is dependent on hematocrit of the individual, a blood-to-plasma ratio of 0.615 was used in the monkey PBPK model based on the defined hematocrit in the monkeys and assuming no blood cell partitioning of DA. The final model parameters are shown in Table 1. 
A

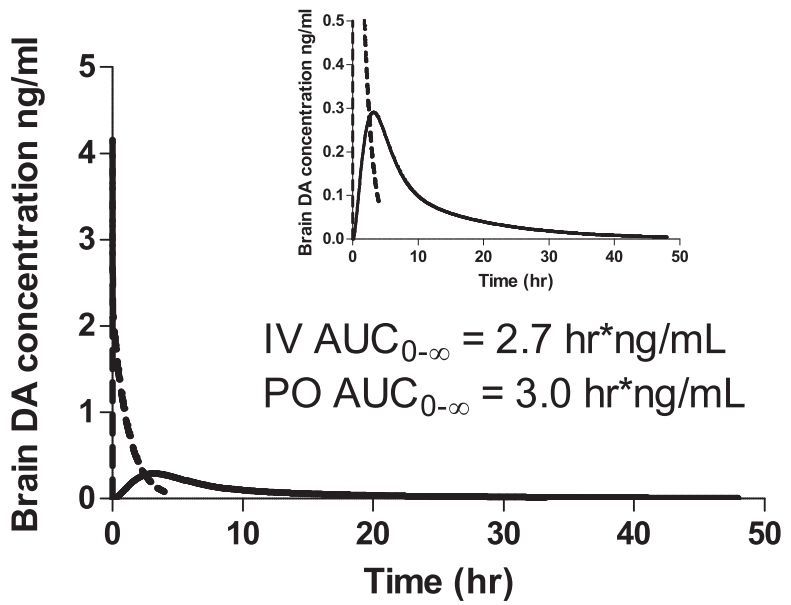

B
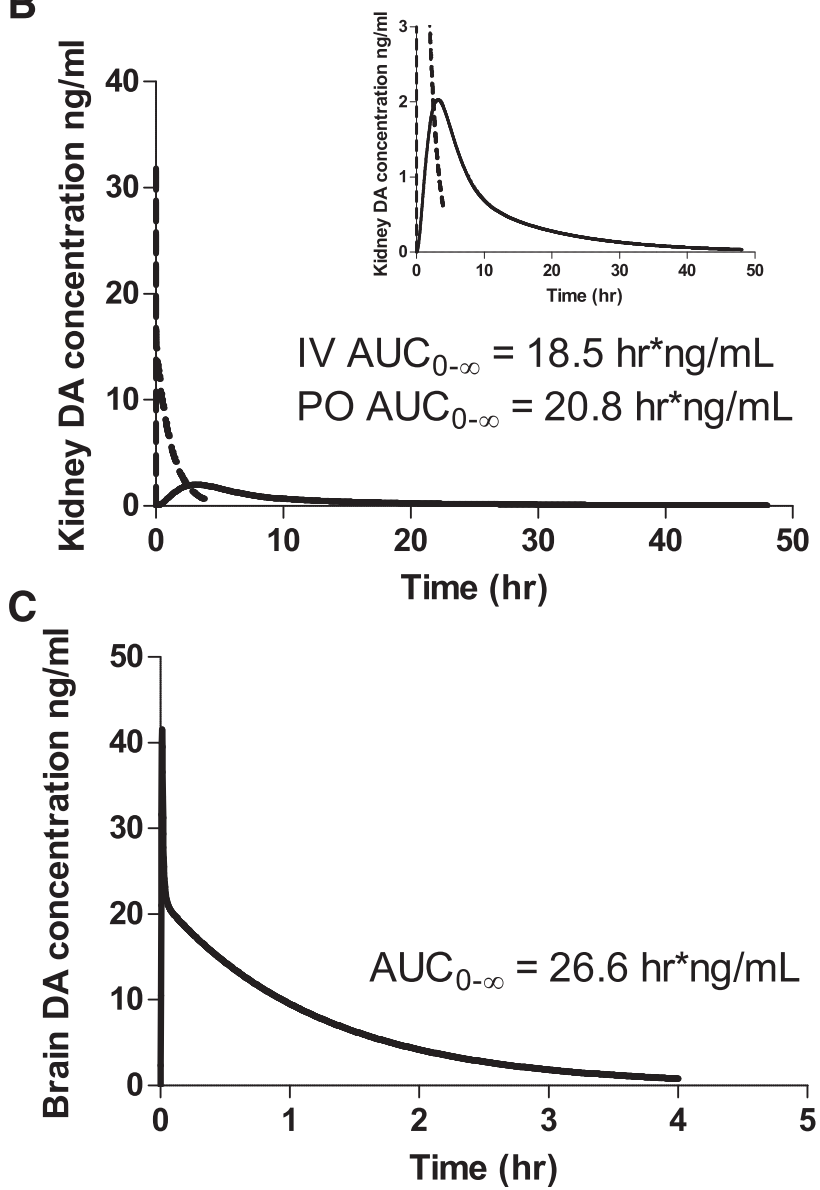

Fig. 6. Simulated concentration-time profiles of DA in monkey brain and kidney. (A) Predicted brain concentration versus time curves for DA following $0.005 \mathrm{mg} / \mathrm{kg}$ i.v. (dashed line) and $0.075 \mathrm{mg} / \mathrm{kg}$ oral (solid line) doses of DA. (B) Predicted kidney concentration versus time curves for DA following $0.005 \mathrm{mg} / \mathrm{kg}$ i.v. (dashed line) and $0.075 \mathrm{mg} / \mathrm{kg}$ oral (solid line) doses of DA. (C) Predicted brain concentration versus time curve for DA following $0.05 \mathrm{mg} / \mathrm{kg}$ i.v. dose of DA. Areas under the concentration curves (AUC) are shown for each simulation. Predicted brain $C_{\max }$ values were $4.2 \mathrm{ng} / \mathrm{ml}$ after $0.005 \mathrm{mg} / \mathrm{kg}$ intravenous dosing, $0.3 \mathrm{ng} / \mathrm{ml}$ following oral $0.075 \mathrm{mg} / \mathrm{kg}$ dosing (A), Predicted kidney $C_{\max }$ values were $32 \mathrm{ng} / \mathrm{ml}$ after $0.005 \mathrm{mg} / \mathrm{kg}$ intravenous dosing, and $2.0 \mathrm{ng} / \mathrm{ml}$ following 0.075 $\mathrm{mg} / \mathrm{kg}$ oral doses (B). The predicted brain $C_{\max }$ was $41.6 \mathrm{ng} / \mathrm{ml}$ following intravenous dose of $0.05 \mathrm{mg} / \mathrm{kg}$ DA (C).

To test the developed DA PBPK model, DA disposition was first simulated in monkeys following administration of single intravenous doses of 5 and $50 \mu \mathrm{g} / \mathrm{kg}$ DA, and the simulations were compared with the observed plasma concentration data obtained in this study and in the previously published study (Truelove and Iverson, 1994) (Fig. 4, A and B; Table 2). The simulated AUC, CL, and $\mathrm{CL}_{\mathrm{r}}$ were all within twofold (between 0.6- and 1.7-fold) of the observed data in the two intravenous dosing studies conducted with a 10-fold range in DA doses and in two different laboratories. DA disposition was also simulated in monkeys following single and multiple oral doses using the developed ADAM model for DA absorption. The simulated AUCs for DA all met the acceptance criteria for the model and were within twofold (1- and 1.2-fold) of the observed data after single oral doses of 0.075 and $0.15 \mathrm{mg} / \mathrm{kg}$ DA (Fig. 4, C and D; Table 3). The PBPK model predicted the flip-flop kinetics of DA with a 12-fold longer simulated half-life after oral dosing than after intravenous dosing. The predicted terminal halflife (absorption half-life) was within 0.8-fold of the observed. In addition to the current study data, the plasma concentrations of DA following 15 days of oral doses of $0.5(\mathrm{mg} / \mathrm{kg}) /$ day DA were also simulated in accordance with the dosing in the prior study (Truelove et al., 1997), which measured single time point concentrations of DA following multiple oral doses (Fig. 4E). The PBPK model captured the multiple dose pharmacokinetics, predicting the single time point plasma concentrations of DA within the twofold criterion (Fig. 4E). The simulation accuracy of urinary excretion of DA was also evaluated. The excretion of DA into urine as a function of time was compared with the data collected in this study and in previously reported studies (Fig. 5). Overall the mean simulated data of DA dose recovery in urine after both intravenous and oral dosing were within twofold of the mean observed data, although interindividual and interday variability within an individual could be over twofold in the observed data.

The predominant sites of DA toxicity appear to be the brain and possibly the kidney. Therefore, the concentration-time curves of DA in the brain and kidney were simulated using the developed PBPK model that incorporated the $K_{\mathrm{p}}$ values for brain and kidney estimated from literature tissue partitioning data. As shown in Fig. 6A, following a single intravenous dose of $5 \mu \mathrm{g} / \mathrm{kg}$ DA, DA is predicted to rapidly distribute into the brain. Following a single oral dose of $0.075 \mathrm{mg} / \mathrm{kg}$ $\mathrm{DA}$, the maximum concentration in the brain is predicted to be reached 3 hours postdose, with prolonged DA exposure in the brain mimicking the flip-flop kinetics observed in plasma. In fact, despite the initial much higher brain concentrations of DA after intravenous dosing, the simulated brain concentrations of DA at later time points were higher following oral dosing than after intravenous dosing. Similarly, the distribution pattern of DA was also simulated in kidney following intravenous and oral doses (Fig. 6B). The kidney concentration-time profiles were similar to those simulated for the brain. High kidney concentrations were reached rapidly following intravenous dosing and slowly after oral dosing, with prolonged exposure in the kidney after oral exposure. Overall, the predicted kidney tissue concentrations were higher than those predicted for the brain. The simulated brain-to-plasma and kidney-to-plasma AUC ratios were 0.066 and 0.46, respectively, reflecting the $K_{\mathrm{p}}$ values observed in rodents. To explore the brain concentration versus time profile of DA following dosing that results in signs of toxicity, the brain concentrations of DA were also simulated in monkeys after $0.075 \mathrm{mg} / \mathrm{kg}$ i.v. (Fig. 6C). These simulations predicted a peak brain concentration of $41.6 \mathrm{ng} / \mathrm{ml}$ and concentrations above $10 \mathrm{ng} / \mathrm{ml}$ up to 1 hour. This suggests that in monkeys brain concentrations above $10 \mathrm{ng} / \mathrm{ml}$ correspond to acute toxicity, as the vomiting in monkeys after $0.075 \mathrm{mg} / \mathrm{kg}$ i.v. dose of DA was restricted to the first 9-62 minutes after dosing (Truelove and Iverson, 1994).

Simulation of DA Disposition in Humans Using PBPK Modeling. A PBPK model of DA toxicokinetics in humans was developed based on the nonhuman primate model. DA disposition in humans following exposures at the current acute reference dose and at exposures similar to 
A

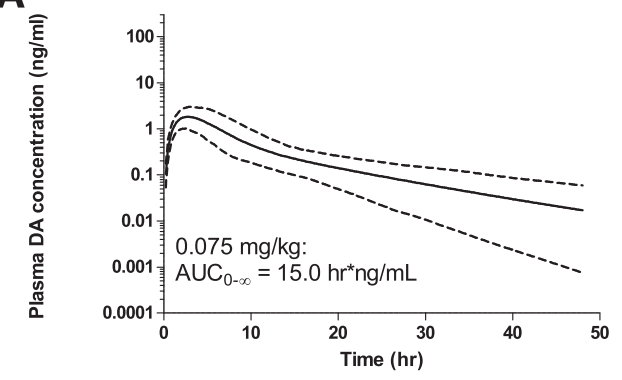

C

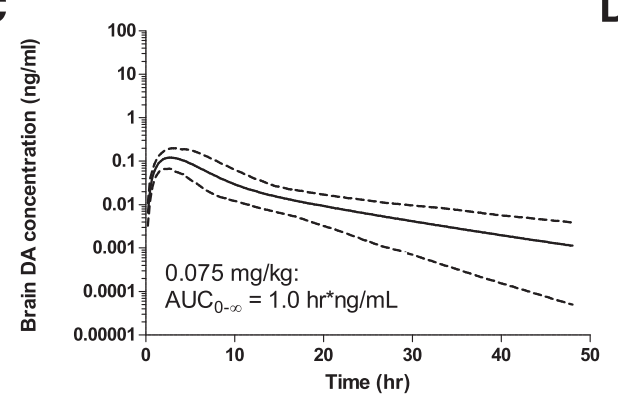

B

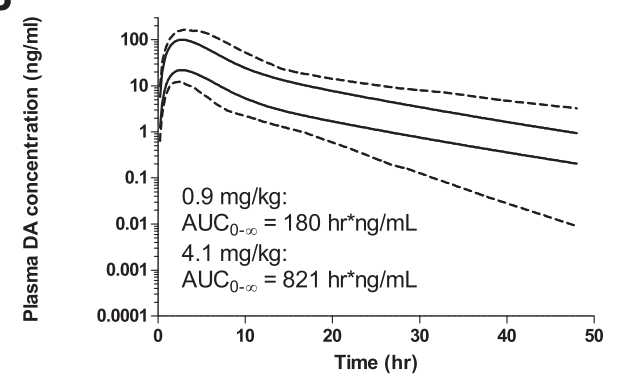

D

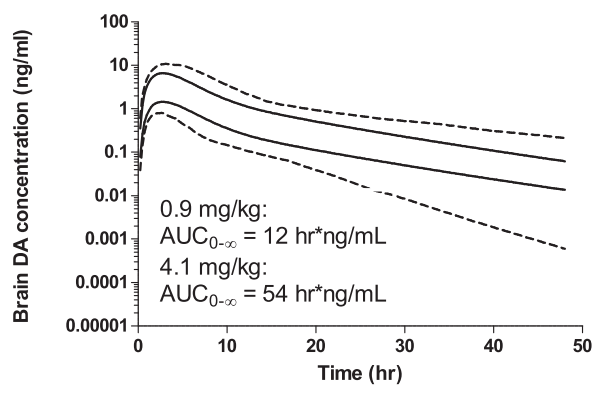

Fig. 7. Simulated concentration-time profiles of DA in humans. (A and C) Predicted plasma (A) and brain (C) concentration versus time curves for DA following consumption of $0.075 \mathrm{mg} / \mathrm{kg}$ of DA by mouth. (B and D) Predicted plasma (B) and brain (D) concentration versus time curves for DA following consumption of $0.9-4.1 \mathrm{mg} / \mathrm{kg}$ of DA orally, the exposure estimated in the DA toxification incident. Dotted lines depict the 95 th and 5 th percentile obtained from the virtual population. The area under the concentration curve (AUC) values are reported in each respective panel. Predicted $C_{\max }$ are (A) 1.8 , (B) 21.8 and $99.3 \mathrm{ng} / \mathrm{ml}$ following 0.9 and $4.1 \mathrm{mg} / \mathrm{kg}$ of DA doses, respectively, (C) $0.1 \mathrm{mg} / \mathrm{ml}$, and (D) 1.4 , and $6.6 \mathrm{ng} / \mathrm{ml}$ following 0.9 and $4.1 \mathrm{mg} / \mathrm{kg}$ of DA doses respectively. those estimated in the DA outbreak in Canada in 1987, was simulated using the human PBPK model. The variability in DA disposition in human population was simulated using the population variability in Simcyp library. The simulated plasma and brain concentration-time curves are shown in Fig. 7. At TDI $(0.075 \mathrm{mg} / \mathrm{kg}$ orally), the exposure in humans is predicted to be about $30 \%-40 \%$ of that observed in monkeys exposed to the same per kilogram dose. Similar to the monkeys, DA exposure in humans after an oral dose was predicted to be prolonged due to the flip-flop kinetics. The brain concentrations of DA in humans were simulated for the doses of $0.9-4.1 \mathrm{mg} / \mathrm{kg}$ DA corresponding to the estimated consumption in the DA outbreak in Canada (Perl et al., 1990). The predicted brain concentrations ranged from 1.4 to $6.6 \mathrm{ng} / \mathrm{ml}$ (Fig. 7) and were similar (within 0.2- to 1-fold) to the simulated threshold brain concentrations in monkeys experiencing DA toxicity.

\section{Discussion}

Over recent decades, toxic algal blooms have increased, resulting in increased risk of DA poisoning in marine mammals and humans who consume contaminated seafood (McCabe et al., 2016). Oral acute reference doses and TDI of DA have been proposed based on toxicity studies in nonhuman primates and estimated lowest observed adverse effect levels in humans (Costa et al., 2010). However, these values were derived without knowledge of DA concentrations in humans, or characterization of the absorption kinetics of DA in humans or nonhuman primates after oral doses. This lack of information is largely due to the limited number of bioanalytical methods to measure DA at low levels in biological samples. In fact, the only plasma concentrations available in a model species after oral exposure are from monkeys dosed at $0.5-0.75(\mathrm{mg} / \mathrm{kg}) /$ day orally (Truelove et al., 1997; Fig. 4). In rats, after oral administration, DA plasma concentrations were below the LLOQ in all samples analyzed (Iverson et al., 1990; Truelove et al., 1996). Existing LC-MS/MS methods lack sufficient sensitivity $($ LLOQ $>7 \mathrm{ng} / \mathrm{ml})$ compared with ELISA (LLOQ $=0.4 \mathrm{ng} / \mathrm{ml})$ (Frame and Lefebvre, 2013) and require large sample volumes $(>500 \mu \mathrm{l})$ (Wang et al., 2012). To allow quantification of DA in biological samples following oral doses similar to current no observed adverse effect level doses, we developed an LC-MS/MS method with sensitivity similar to the ELISA. This method will be useful for future evaluation of DA kinetics and exposures in experimental animals, wildlife, and in humans consuming potentially contaminated seafood.

This study provides the first characterization of the absorption kinetics of DA following oral exposure in mammals and shows that DA is subject to pronounced flip-flop kinetics with a slow absorption from the gut. Due to the flip-flop kinetics, the terminal half-life of DA following oral exposure is prolonged compared to what would have been expected from the intravenous data. The bioavailability of $7 \%$ determined in this study is in excellent agreement with the previous work suggesting $<10 \%$ bioavailability of DA (Truelove and Iverson, 1994; Truelove et al., 1997). This low bioavailability is consistent with the high polarity and fully charged state of DA at physiological pH (Vera-avila et al., 2011) and possible predominantly paracellular absorption of DA. The extent of absorption and the flip-flop kinetics of DA following oral dosing were predicted using the $\mathrm{P}_{\text {eff }}$ value for DA and the monkey ADAM model in Simcyp. As the mechanistic absorption model predicted DA absorption kinetics in monkeys, a DA PBPK model was developed to predict DA toxicokinetics in humans. The PBPK model predicted flip-flop kinetics for DA also in humans, suggesting a prolonged exposure to DA after consumption of contaminated seafood. Yet, it is likely that uptake and efflux transporters contribute to DA absorption kinetics, which is not captured in the current model. In a prior study, apical-to-basolateral transport of DA in Caco-2 cells was shown to be decreased by $31.5 \%$ when DA was incubated with probenecid $(100 \mathrm{mM})$, a nonspecific inhibitor of anion transport (Kimura et al., 2011), suggesting transporter involvement in the intestinal absorption of DA.

The developed monkey PBPK model was also used to simulate the brain and kidney concentrations of DA following intravenous and oral doses of DA. DA concentrations were previously reported in the kidney, liver, heart, and hippocampus of mice (Funk et al., 2014) and in brain and cerebrospinal fluid in pregnant rats (Maucher Fuquay et al., 2012a). The simulated brain and kidney distribution in monkeys is in excellent agreement with prior data from rats showing rapid distribution of DA into tissues after intravenous dosing (Maucher Fuquay et al., 2012a). The simulated fast distribution to the brain is also in agreement with the fast onset of vomiting (2-14 minutes) in monkeys dosed with $50 \mu \mathrm{g} / \mathrm{kg}$ intravenously and the duration of the vomiting restricted to the first 
9-62 minutes after intravenous dosing (Truelove and Iverson, 1994). The simulated brain concentration-time curves after oral exposure in either monkeys or humans (Figs. 6 and 7) provide insight into the prolonged onset of signs of DA toxicity following consumption of contaminated mussels by humans. In the 1987 DA outbreak, the onset for symptoms after consumption of DA contaminated mussels was between 15 minutes and 38 hours (median 5.5 hours) (Perl et al., 1990). As shown in Figs. 6 and 7, following consumption of DA, the time to reach maximum DA concentrations in the brain is expected to be delayed. The PBPK models predicted similar (within 1- to 5-fold) peak brain DA concentrations in the human poisoning event and as brain threshold concentrations in monkeys dosed intravenously and experiencing DA toxicity. The PBPK models also predicted a much longer duration of exposure in the brain following oral dosing than what is observed after intravenous dosing. This may be important for chronic toxicity of asymptomatic exposures to DA, that lead to the reported sensitization to DA and to epigenetic changes (Hiolski et al., 2014; Lefebvre et al., 2017). However, the current model does not incorporate possible transporter contributions to brain distribution of DA, which requires further study. The DA analogs kainic acid and dehydrokainic acid have been shown to have low blood-brain barrier permeability but not require active transport for uptake to the brain (Gynther et al., 2015). Efflux transporters, such as MRP5 may, however, restrict brain exposure to DA and cause some species differences in brain distribution, as DA and kainic acid have been shown to be substrates for MRP5 (Jansen et al., 2015).

The majority of DA clearance is believed to be via the kidney, because in rats DA is entirely eliminated via the kidney through glomerular filtration (Suzuki and Hierlihy, 1993). Hence, renal impairment has been considered in estimating human safety factors for DA. However, the data presented here and the previous study in cynomolgus monkeys (Truelove and Iverson, 1994) show less than complete urinary recovery $(42 \%-71 \%)$ of DA. This suggests that other elimination pathways of DA exist in addition to renal excretion. Biliary secretion by efflux transporters likely contributes to DA clearance. DA was detected in fecal samples in this study after intravenous dosing, and DA has been found in the bile of California sea lions (15-344.7 $\mathrm{ng} / \mathrm{ml} \mathrm{DA}$ ) and harbor porpoise (11.7 ng/ml DA) (Rust et al., 2014). In addition, consistent with biliary secretion of DA, the plasma-concentration time curves of DA following oral dosing to monkeys had a characteristic second peak for DA concentrations (around 16-24 hours in Fig. 3C), suggesting some extent of enterohepatic recycling. In rats, probenecid caused a significant increase in plasma DA levels (Robertson et al., 1992) but had no effect on DA renal clearance (Suzuki and Hierlihy, 1993). In mice, probenecid also increased DA concentrations in kidney tissue and serum (Funk et al., 2014). These findings are consistent with hepatic interaction between probenecid and efflux transporters responsible for DA excretion. Further studies are needed to evaluate the quantitative significance of biliary secretion and possible metabolism in DA clearance, and to identify potential transporters responsible for biliary secretion of DA.

The overall renal clearance of DA in monkeys was lower than the GFR, suggesting that, in addition to glomerular filtration, significant DA reabsorption occurs. Due to its high charge state and polarity, passive transcellular reabsorption of DA in the kidney tubule is not expected. Indeed, the renal clearance of DA in the rat has been shown to be similar to the GFR (Suzuki and Hierlihy, 1993). The observation of significant reabsorption of DA in monkeys is consistent with the previous findings after intravenous dosing of DA to monkeys (Truelove and Iverson, 1994). These data suggest that active transport contributes to the reabsorption of DA in monkeys. As the identity and quantitative importance of specific transporters in DA renal clearance is not known, the observed renal clearance of $0.98(\mathrm{ml} / \mathrm{min}) / \mathrm{kg}$ in monkeys was used for the PBPK model. Although the renal clearance and urinary excretion of DA had high inter- and intraindividual variability, the developed monkey PBPK model predicted the urinary excretion of DA following intravenous and oral dosing and single and multiple dose exposures across studies (Fig. 5).

In conclusion, this study shows that DA has pronounced flip-flop kinetics in monkeys following oral dosing, resulting in lower peak concentrations and longer exposures than would be expected based on intravenous kinetics and with rapid absorption. The toxicokinetic data together with the PBPK model strongly suggest that efflux transporters in the liver are an important contributor to DA elimination. The developed PBPK model provides a powerful tool for future evaluation of DA disposition in acute and chronic toxicology studies, and a framework for future exploration of contribution of transporters to DA clearance and distribution to target organs. The monkey PBPK model also provided a basis for a DA PBPK model in humans to support extrapolation of toxicity data between species and exposure levels. The results of this study provide important new information to evaluate exposure-toxicity relationships of DA to aid in assessment of human DA exposure risks in different populations.

\section{Acknowledgments}

We thank Courtney Stanley, Caroline Kenney, and the staff at the Infant Primate Research Laboratory and the UW National Primate Research Center for help in conducting this project.

\section{Authorship Contribution}

Participated in research design: Jing, Petroff, Crouthamel, Grant, Burbacher, Isoherranen.

Conducted experiments: Jing, Shum, Petroff, Crouthamel, Topletz. Performed data analysis: Jing, Shum, Topletz, Burbacher, Isoherranen.

Wrote or contributed to the writing of the manuscript: Jing, Petroff, Shum, Grant, Burbacher, Isoherranen.

\section{References}

Barbaro E, Zangrando R, Barbante C, and Gambaro A (2016) Fast and sensitive method for determination of domoic acid in mussel tissue. Sci World J 2016:8404092.

Costa LG, Giordano G, and Faustman EM (2010) Domoic acid as a developmental neurotoxin. Neurotoxicology 31:409-423.

Du X, Peterson W, Fisher J, Hunter M, and Peterson J (2016) Initiation and development of a toxic and persistent pseudo-nitzschia bloom off the Oregon coast in spring/summer 2015. PLoS One 11:e0163977

Frame E and Lefebvre K (2013) ELISA methods for domoic acid quantification in multiple marine mammal species and sample matrices. U.S. Dept. Commer., NOAA Tech. Memo. NMFSNWFSC-122.

Funk JA, Janech MG, Dillon JC, Bissler JJ, Siroky BJ, and Bell PD (2014) Characterization of renal toxicity in mice administered the marine biotoxin domoic acid. J Am Soc Nephrol 25: $1187-1197$.

Gynther M, Petsalo A, Hansen SH, Bunch L, and Pickering DS (2015) Blood-brain barrier permeability and brain uptake mechanism of kainic acid and dihydrokainic acid. Neurochem Res 40: 542-549.

Hiolski EM, Kendrick PS, Frame ER, Myers MS, Bammler TK, Beyer RP, Farin FM, Wilkerson HW, Smith DR, Marcinek DJ, et al. (2014) Chronic low-level domoic acid exposure alters gene transcription and impairs mitochondrial function in the CNS. Aquat Toxicol 155:151-159.

Iverson F, Truelove J, Tryphonas L, and Nera EA (1990) The toxicology of domoic acid administered systemically to rodents and primates. Can Dis Wkly Rep 16 (Suppl 1E):15-18, discussion $18-19$

Jansen RS, Mahakena S, de Haas M, Borst P, and van de Wetering K (2015) ATP-binding cassette subfamily $\mathrm{C}$ member 5 (ABCC5) functions as an efflux transporter of glutamate conjugates and analogs. J Biol Chem 290:30429-30440.

Jing J, Nelson C, Paik J, Shirasaka Y, Amory JK, and Isoherranen N (2017) Physiologically based pharmacokinetic model of all-trans-retinoic acid with application to cancer populations and drug interactions. J Pharmacol Exp Ther 361:246-258.

Kimura O, Kotaki Y, Hamaue N, Haraguchi K, and Endo T (2011) Transcellular transport of domoic acid across intestinal Caco-2 cell monolayers. Food Chem Toxicol 49:2167-2171.

Lefebvre KA, Bargu S, Kieckhefer T, and Silver MW (2002) From sanddabs to blue whales: the pervasiveness of domoic acid. Toxicon 40:971-977.

Lefebvre KA, Frame ER, Gulland F, Hansen JD, Kendrick PS, Beyer RP, Bammler TK, Farin FM, Hiolski EM, Smith DR, et al. (2012) A novel antibody-based biomarker for chronic algal toxin exposure and sub-acute neurotoxicity. PLoS One 7:e36213.

Lefebvre KA, Kendrick PS, Ladiges W, Hiolski EM, Ferriss BE, Smith DR, and Marcinek DJ (2017) Chronic low-level exposure to the common seafood toxin domoic acid causes cognitive deficits in mice. Harmful Algae 64:20-29. 
Lefebvre KA and Robertson A (2010) Domoic acid and human exposure risks: a review. Toxicon 56:218-230.

Lewitus AJ, Horner RA, Caron DA, Garcia-Mendoza E, Hickey BM, Hunter M, Huppert DD, Kudela RM, Langlois GW, Largier JL, et al. (2012) Harmful algal blooms along the North American west coast region: history, trends, causes, and impacts. Harmful Algae 19:133-159.

Mariën K (1996) Establishing tolerable dungeness crab (cancer magister) and razor clam (Siliqua patula) domoic acid contaminant levels. Environ Health Perspect 104:1230-1236.

Maucher Fuquay J, Muha N, Wang Z, and Ramsdell JS (2012a) Elimination kinetics of domoic acid from the brain and cerebrospinal fluid of the pregnant rat. Chem Res Toxicol 25:2805-2809.

Maucher Fuquay J, Muha N, Wang Z, and Ramsdell JS (2012b) Toxicokinetics of domoic acid in the fetal rat. Toxicology 294:36-41.

McCabe RM, Hickey BM, Kudela RM, Lefebvre KA, Adams NG, Bill BD, Gulland FMD, Thomson RE, Cochlan WP, and Trainer VL (2016) An unprecedented coastwide toxic alga bloom linked to anomalous ocean conditions. Geophys Res Lett 43:10366-10376.

Mckibben SM, Peterson W, Wood AM, Trainer VL, Hunter M, and White AE (2017) Climatic regulation of the neurotoxin domoic acid. Proc Natl Acad Sci U S A 114:239-244.

Mos L (2001) Domoic acid: a fascinating marine toxin. Environ Toxicol Pharmacol 9:79-85.

Perl TM, Bédard L, Kosatsky T, Hockin JC, Todd EC, and Remis RS (1990) An outbreak of toxic encephalopathy caused by eating mussels contaminated with domoic acid. $N$ Engl J Med $\mathbf{3 2 2}$ $1775-1780$.

Pulido OM (2008) Domoic acid toxicologic pathology: a review. Mar Drugs 6:180-219.

Robertson H, Renton K, Kohn J, and White T (1992) Patterns of Fos expression suggest similar mechanisms of action for the excitotoxins domoic and kainic acid. Ann N Y Acad Sci 648 330-334.

Rodgers T and Rowland M (2006) Physiologically based pharmacokinetic modelling 2: predicting the tissue distribution of acids, very weak bases, neutrals and zwitterions. J Pharm Sci 95 1238-1257.

Rust L, Gulland F, Frame E, and Lefebvre K (2014) Domoic acid in milk of free living California marine mammals indicates lactational exposure occurs. Mar Mammal Sci 30:1272-1278.

Scholin CA, Gulland F, Doucette GJ, Benson S, Busman M, Chavez FP, Cordaro J, DeLong R, De Vogelaere A, Harvey J, et al. (2000) Mortality of sea lions along the central California coas linked to a toxic diatom bloom. Nature 403:80-84.
Shah VP, Midha KK, Findlay JW, Hill HM, Hulse JD, McGilveray IJ, McKay G, Miller KJ, Patnaik RN, Powell ML, et al. (2000) Bioanalytical method validation-a revisit with a decade of progress. Pharm Res 17:1551-1557.

Suzuki CA and Hierlihy SL (1993) Renal clearance of domoic acid in the rat. Food Chem Toxico 31:701-706.

Todd E (1993) Domoic acid and amnesic shellfish poisoning - a review. J Food Prot 56:69-83. Truelove J and Iverson F (1994) Serum domoic acid clearance and clinical observations in the cynomolgus monkey and Sprague-Dawley rat following a single i.v. dose. Bull Environ Contam Toxicol 52:479-486.

Truelove J, Mueller R, Pulido O, and Iverson F (1996) Subchronic toxicity study of domoic acid in the rat. Food Chem Toxicol 34:525-529.

Truelove J, Mueller R, Pulido O, Martin L, Fernie S, and Iverson F (1997) 30-day oral toxicity study of domoic acid in cynomolgus monkeys: lack of overt toxicity at doses approaching the acute toxic dose. Nat Toxins 5:111-114.Vera-avila LE, Marín-pérez DY, and Covarrubias-herrera R (2011) Trace level determination of domoic acid in seawater by off-line / on-line solidphase extraction coupled to HPLC-UV. J Mex Chem Soc 55:65-71.

Viswanathan CT, Bansal S, Booth B, DeStefano AJ, Rose MJ, Sailstad J, Shah VP, Skelly JP, Swann PG, and Weiner R (2007) Quantitative bioanalytical methods validation and implementation: best practices for chromatographic and ligand binding assays. Pharm Res 24:1962-1973.

Walter JA, Leek DM, and Falk M (1992) NMR study of the protonation of domoic acid. Can J Chem 70:1156-1161.

Wang Z, Maucher-Fuquay J, Fire SE, Mikulski CM, Haynes B, Doucette GJ, and Ramsdell JS (2012) Optimization of solid-phase extraction and liquid chromatography-tandem mass spectrometry for the determination of domoic acid in seawater, phytoplankton, and mammalian fluids and tissues. Anal Chim Acta 715:71-79.

Address correspondence to: Nina Isoherranen, Department of Pharmaceutics, University of Washington, Health Science Building Room H-272M, Box 357610, Seattle, WA 98195-7610. E-mail: ni2@uw.edu 